\title{
LINGUAGENS OS REGISTROS EM DIÁRIOS DE BORDO E A PRÁTICA REFLEXIVA DOCENTE
}

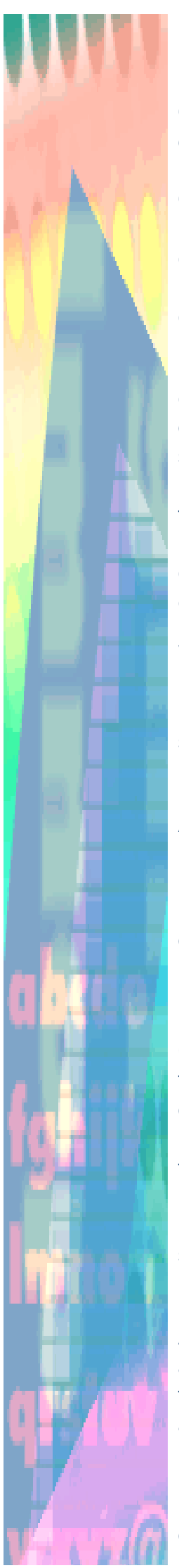

\author{
Marizete Righi Cechin
}

O presente texto trata do uso dos diários de bordo como auxílio ao professor para desenvolver-se criticamente através da ação de pensar sobre sua prática.

O recorte no estudo dos diários de bordo representa apenas uma parte de uma pesquisa maior que está sendo desenvolvida no curso de pós-graduação em educação na Universidade Federal de Santa Maria (UFSM) a nível de mestrado. Essa pesquisa trata de ações que valorizam o diálogo (nos moldes freireanos) para a construção de pensamentos críticos de acadêmicos em fase final do curso.

Para desenvolver o uso de diários na prática docente, trabalhou-se com acadêmicos estagiários do curso de letras da UFSM. A ressignificação da prática educativa a partir de leituras de textos construídos pelos próprios acadêmicos estagiários a respeito de suas práticas pedagógicas com o propósito de melhorar as ações docentes enquanto professores investigadores exigiu uma parceria docente entre o professor regente da turma, Prof. Dr. Marcos Gustavo Richter, também orientador da dissertação, com a Profa. Mestranda Marizete Righi Cechin. Nessa parceria, buscou-se práticas educacionais dialógicas que valorizam a autonomia do acadêmico, o trabalho em grupo e o pensar reflexivo sobre a elaboração e execução de atividades.

Visando a construção reflexiva sobre o fazer pedagógico desses acadêmicos, futuros profissionais no mercado, trabalhou-se com a reflexão dos materiais escritos pelos próprios alunos sobre a prática de estágio. Estudos mostram que a ação de escrever sobre o que se passa em sala de aula contribui para uma formação mais crítica do ato pedagógico (ALARCÃO (1996), PORLÁN \& MARTíN (1997)).

A escrita sobre o que se passa em sala de aula pode começar com duas perguntas básicas: o que é que se fez? Por quê? Embora pareçam questões simples, as respostas são complexas. Geralmente esse tipo de indagação exige tempo para pensar sobre o que se passou em aula e implica questionar a própria prática, fatores que impedem muitos docentes de se indagarem sobre o que fazem enquanto professores. E se a indagação não acontece, a escrita sobre essas questões muito menos.

Geralmente o primeiro contato do graduando com alunos das redes de ensino fundamental e médio acontece ainda na faculdade, durante a fase do estágio. Esse é o momento em que os primeiros desafios da carreira docente aparecem: salas com um número significativo de alunos, estrutura física carente, falta de recursos tecnológicos, biblioteca desatualizada, entre outros fatores influenciam todo um planejamento de unidade de aula. Caso esse estagiário não busque, dentro das possibilidades, contribuir para uma qualidade de ensino em termos reflexivos estará somando-se à grande massa da população que não acredita que a educação promova mudanças sociais.

A busca do ensino reflexivo que envolve um posicionamento frente à realidade não acontece do dia para a noite. É um processo lento e longo. A importância de se trabalhar com o jovem graduando nesse construir-se politicamente e reflexivamente ainda na faculdade está em acelerar sua iniciação ao pensamento reflexivo docente.

Uma das possibilidades de se trabalhar a construção de uma atuação crítica frente à realidade é se habituar a pensar o próprio quefazer (palavra usada por Paulo Freire que designa um fazer consciente e crítico, um empreendimento que une teoria e 
prática em uma ação pedagógica concreta), e, nesse sentido, o ato de escrever o que se passa para depois consultar apresenta-se como uma alternativa concreta.

As narrativas que relatam os fatos para uma consulta posterior são chamadas de diário de bordo (log), diário íntimo (diary) e registro quotidiano (journal). O primeiro caracteriza-se pelo caráter objetivo dos acontecimentos; o segundo, além da objetividade do texto, permite o afastamento do autor possibilitando a reflexão do ato educativo através do diálogo do autor com ele próprio e com sua ação; o terceiro inclui as características de ambos os tipos de narrativas anteriores mas com a vantagem de reconstruir a experiência vivida em termos de fatos e sentimentos possibilitando a tomada de consciência daquilo que foi objetivo e subjetivo (ALARCÃO, 1996).

No texto, adota-se a palavra diário com o mesmo sentido que o registro quotidiano descrito acima assume.

Uma das vantagens do diário e do seu uso constante é que ele permite ao autor refletir sobre sua prática e a dinâmica do seu trabalho. O diário pode ser entendido como "um guia de reflexão sobre a prática, favorecendo a tomada de consciência do professor sobre seu processo de evolução e sobre seus modelos de referência" (PORLÁN \& MARTíN, 1997, p.19/20).

O começo de um diário, geralmente, é marcado por uma visão simplificada da realidade. Os fatos parecem não ter ligação, não se consegue estabelecer elos entre diferentes situações ou acontecimentos. A tendência é atribuir aos aspectos de personalidade certos padrões de comportamento ao invés de analisar as variáveis do contexto ou influências de outras pessoas.

A princípio, a subjetividade impregnada na atividade escolar parece estar presente nas narrativas do diário na forma espontânea que a dinâmica geral da classe é descrita. A superação da subjetividade pode acontecer se pouco a pouco se cria um "grau de diferenciação consciente entre o que se descreve espontaneamente e a análise mais sossegada, sistemática e racional que posteriormente, ou paralelamente, se pode fazer disso" (PORLÁN \& MARTíN, 1997, p.25).

A partir dessa diferenciação, a percepção dos problemas práticos e dos dilemas teóricos se tornam mais evidentes, ou seja, quanto mais se diferenciam as incidências, os valores e as interpretações, mais se destacam os problemas da dinâmica da classe.

O diário é uma fonte em que se reconhecem os problemas e, com eles, a compreensão da complexidade da realidade. O problema pode ser uma ação, uma situação ou um planejamento. À medida que os problemas vão sendo investigados, eles se tornam mais claros e delimitados. "Num primeiro momento se formula uma descrição muito genérica e pouco reflexiva" (PORLÁN \& MARTíN, 1997, p.27) da realidade. Aos poucos e progressivamente, a problemática começa a ficar mais esclarecida e a atenção do autor começa a circular e envolver tal problemática, buscando uma análise mais profunda e direcionando-se para as possíveis causas, origens e conseqüências do problema.

Não raramente, as observações relatam a superposição de fatos: de um lado, a configuração acadêmica da estrutura e dinâmica das aulas que obrigam o professor a seguir uma série de princípio dentre os quais

"a necessidade de dar o programa, de trabalhar um certo número de conteúdos, de manter uma certa aparência de controle homogêneo, etc. Por outro, uma trama oculta de relações informais que refletem (...) uma autêntica transformação de interesses, conhecimentos e aprendizagens reais" 
Na sala, geralmente há um grupo de alunos que aceitam o jogo de aparências que a escola quer passar e outro grupo que não aceita, evidenciando as contradições do sistema.

Quando no diário aparece o grupo que não quer aceitar as aparências impostas pelo sistema, geralmente a descrição das causas para a atitude de desordem dos alunos estão nos alunos. O professor alega que eles "não possuem capacidades suficientes", "que apenas distraem-se", "que não mostram interesse por nada".

Uma das razões do professor atribuir o problema ao aluno está na suas crenças e valores. Ele acredita ou deseja que todos os seus alunos tenham o mesmo nível de interesse, participação e conhecimento contribuindo para uma única estratégia de trabalho; no entanto, o que o docente enfrenta é a constatação da diversidade da realidade.

Essas crenças e valores fazem parte das concepções que os docentes têm da realidade. São essas concepções que guiam e orientam as atuações desses profissionais em sala de aula. As concepções de aluno (como aprendem, como se facilita essa aprendizagem, etc), do papel do professor (sua autoridade, fins pedagógicos, etc), da matéria (caráter absoluto ou relativo do conhecimento, recursos, etc) e as concepções do ambiente, tais como relações psicossociais dentro e fora da aula, relações de poder, entre outros, são construídos ao longo dos tempos. Caso não seja oportunizada ao profissional a construção crítica das concepções vigentes de mundo, ele adotará construções alheias da realidade como suas, fortalecendo tais concepções e aumentando a resistência a mudanças.

A sustentação e a ampliação de uma dada concepção de realidade já padronizada pode ser causada pelo contraste do que se acredita com uma outra concepção (por possibilitar a análise de problemas sob outros pontos de vista). Mas também o contraste de uma concepção com outra pode causar mudanças. As mudanças de concepções (e conseqüentemente da prática docente) podem ocorrer também no contraste com outras realidades ou pontos de vista (PORLÁN \& MARTíN, 1997).

A importância de se trabalhar com o diário também se dá pela possibilidade de se rever concepções de realidade que foram introjetadas sem se perceber as conseqüências que elas causam.

A discussão oriunda dos diários "não deve direcionar-se somente a problematizar a prática, mas também a buscar novas soluções bem fundamentadas, elaborando conjuntamente hipóteses de investigação" (PORLÁN \& MARTíN, 1997, p.67). Assim, o diário não somente deve recolher informações empíricas, mas também incorporar novas referências teóricas.

Desse modo, o uso do diário como um recurso para a formação crítica do aluno estagiário fez parte da experiência docente dos acadêmicos durante o segundo semestre de 1998.

Os sujeitos envolvidos somavam uma média de 30 alunos divididos em duas turmas em fase de conclusão de curso, portanto cursando a disciplina de prática de ensino (incoerentemente, esses profissionais habitualmente apenas entram em contato com alunos do ensino fundamental e médio no último semestre do ensino básico). 0 desafio proposto às turmas foi de trabalhar a disciplina "Análise crítica das teorias do ensino do Português" associada à realidade que eles estavam vivenciando no estágio.

As turmas, divididas em grupos, comprometeram-se em fazer um relatório (diário) das atividades docentes. Nesse relatório, interessava os problemas lingüísticos relacionados às teorias do ensino do português enfrentados e as alternativas 
encontradas para solucioná-los. Entre os problemas enfrentados durante a fase de estágio, um se destaca: como é possível valorizar os textos dos relatórios do estágio (leitura de mundo) para a melhor qualidade das aulas de quem os escreveu?

Através da troca de informações entre grupos tendo como base os escritos, foram-se ressignificando as práticas docentes. Os acadêmicos trocavam informações dentro do grupo e com o grande grupo a respeito das situações enfrentadas no estágio. Colocavam como deram conta da situações, as conseqüências e as novas situações que surgiram oriundas da situação anterior.

Esse olhar novamente a prática à luz das teorias do ensino do português permitiu aos acadêmicos olharem-se de fora, perceberem-se sujeitos cognoscentes diante do objeto cognoscível que os mediatizou — no caso, os relatórios.

Tais encontros para a reflexão sobre a ação transformaram-se em meio para a apropriação progressiva, pelos acadêmicos, dos seus relatos. Explicando: os estagiários conscientizaram-se gradativamente do valor e do papel dos relatórios como instrumentos, no sentido vygotskiano do termo; ao perceberem que tinham nas mãos um artefato mediador para melhorarem suas funções cognitivas superiores enquanto professores emergentes, foram desenvolvendo a capacidade de interiorizar a criticidade que se espera de um educador reflexivo. O produto final do percurso realizado foi a eclosão da autonomia, uma das metas fundamentais do trabalho realizado.

A concepção metodológica que permeou a pesquisa foi a investigação-ação emancipatória. Essa concepção valoriza os participantes envolvidos no processo como sujeitos atores de seu trabalho. Ela implica um comprometimento constante dos envolvidos desde o planejamento de uma ação até a concretude e análise dessa ação.

Nessa concepção, a realidade é concebida como histórica, construída pelo homem e transformada por ele através do trabalho. O homem é tido como um ser em evolução e transformação, um "estar sendo" constante. Assim, a ação pensada do homem é realizada não individualmente, mas em parceria com outros homens que almejam transformar uma realidade que se apresenta inquieta.

A concepção da realidade em mutação implica conceber o conhecimento também em constante mudança. Desse modo, as atividades em sala de aula originam-se dos fatos ou circunstâncias da realidade de cada turma. Ou seja, para cada dupla de estagiário, as situações pedagógicas se apresentam de maneira singular e diferente das outras duplas, exigindo uma análise da realidade genuína para que o trabalho possa envolver atrativamente a maioria dos alunos.

Questões como "A quem educar? Quem educa? Com que fins? Por que meios?" (PINTO, 1997, p.46) envolvem o ato pedagógico contribuindo para que cada aluno pense sobre a relação que há entre o conteúdo e a forma da educação para determinado contexto e busque uma resposta cada vez mais apurada em termos de criticidade.

A escolha da investigação-ação como concepção de pesquisa se dá por ela se apresentar flexível às realidades. Kaufman e Rodriguez a desenvolvem trabalhando leitura e produção de textos em El Palomar, província de Buenos Aires. Jolibert e seus colaboradores tratam do ensino de diferentes tipos de textos em Écuen, na França. Goulart trabalha o ensino da geografia em Porto Alegre, RS. Amaral e Ribeiro (In: ALARCÃO, 1996) tratam do papel do supervisor de estágio usando a investigação-ação como concepção metodológica para desenvolver o pensamento reflexivo dos acadêmicos em Lisboa, Portugal.

ALARCÃO (1996, p.117-8) deixa claro que a 
"investigação-ação assume um papel importante na formação de professores dado que os professores que recorrem a esta metodologia fazem mais perguntas acerca do ensino e do modo como poderiam fazer diferentemente e pedem ajuda para compreender os resultados das suas aulas e informações acerca de como tomar decisões sobre o ensino".

Além de destacar essas características no profissional docente, a investigação-ação apresenta uma sistematicidade de pesquisa que contempla a espiral lewiniana. Ou seja, ciclos sucessivos de planejamento, ação, observação e reflexão. Desse ciclo, origina-se outro ciclo formando uma espiral que cada vez mais aprofunda o entendimento dos envolvidos numa determinada realidade que está sendo estudada (CARR e KEMMIS, 1988).

Através dessa dinâmica, os fatos que a princípio surgiam na sala de aula sem relação começam a se apresentarem relacionados. A relação torna-se mais clara a partir dos diálogos que se estabelecem entre os envolvidos. Os diários construídos pelos acadêmicos passaram por esse processo de polimento. Primeiramente os diários apresentavam uma descrição da realidade aparente. Destacavam-se comentários descritivos e isolados. Com o passar do tempo, os textos tendiam a abraçar a realidade descrita contemplando a análise sobre os fatos, agora relacionados. Esse segundo momento contribuía mais significativamente para que a espiral progredisse, pois os planejamentos tinham um apoio mais fundamentado tanto na relação entre os fatos quanto na explicação teórica.

A experiência do uso dos diários com os acadêmicos de Letras possibilitou que a opinião dos elementos do grupo fosse ouvida pelo grupo todo. Cada dupla tinha seu diário que compartilhava com o grupo que fazia parte (cada turma tinha quatro grupos aglomerados por atuarem com séries semelhantes). Esse grupo compartilhava entre si as realidades da sala de aula, as atividades propostas, os resultados, as conclusões, as novas perspectivas e assim por diante. A contribuição do grande grupo se dava sobre alguns aspectos que o grupo escolhia para apresentar.

A escolha dos tópicos que seriam apresentados para toda a turma se baseava em aspectos que o grupo considerasse relevante para comprovar as vantagens ou as desvantagens da gramática tradicional, estrutural ou gerativo-transformacional.

O diário servia de apoio para esse resgate do estágio. Ou seja, os acadêmicos tinham na disciplina do Português VIII a fundamentação teórica dessas vantagens e desvantagens e o apoio para construírem suas unidades de aula do estágio. O diário significava não só o resultados da combinação entre teoria e prática, mas também o registro das ações pedagógicas analisadas mais criticamente.

Considerando que "se a teoria e a prática são algo indicotomizável, a reflexão sobre a ação ressalta a teoria, sem a qual a ação (ou a prática) não é verdadeira" (FREIRE, 1980, p.40), a pesquisa apontou que o trabalho de registrar as práticas e ler tais registros criticamente é extremamente interessante, pois nos memoriais os acadêmicos não escrevem tudo o que realmente consideram importante, mas nas falas das leituras que fazem sobre o que escreveram manifestam o que estava oculto. Essa ressignificação, ou seja, o novo sentido que o texto (a prática) assume associado à teoria fez com que eles pensassem mais criticamente suas práticas e passassem a vê-las como práticas de transformação social.

\section{BIBLIOGRAFIA}

ALARCÃO, Isabel. Formação reflexiva de professores: estratégias de superação. Lisboa: Porto Editora, 1996. 
CARR, W. \& KEMMIS, S. Teoria crítica de la enseñanza: Investigaciónacción en la formación del profesorado. Barcelona: Martinez Roca, 1988.

FREIRE, Paulo. Extensão ou comunicação. 5 ed. Rio de Janeiro: Paz e Terra, 1980.

FREIRE, Paulo. Pedagogia do oprimido. 18 ed. Rio de Janeiro: Paz e Terra, 1988.

GOULART, Lígia B. Dificuldades para aprender geografia: uma proposta de oficina de zona de desenvolvimento proximal. Porto Alegre: PUC. 1993. (Dissertação de mestrado)

JOLIBERT, Josette. Formando crianças produtoras de textos. Porto Alegre: Artes Médicas, 1994.

KAUFMAN, A.M. \& RODRIGUEZ, M. E. Escola, Leitura e produção de textos. Porto Alegre: Ates Médicas, 1995.

OLIVEIRA, Marta Kohl de. Vygotsky: aprendizado e desenvolvimento: um processo sócio-histórico. 3 ed. São Paulo: Scipione: 1995

PINTO, Álvaro Vieira. Sete lições sobre educação de adultos. 10 ed. São Paulo: Cortez, 1997.

PORLÁN, Rafael \& MARTÍN, José. El diario del profesor. Sevilla: Díada Editora, 1997.

[índice] [ resumo ]

